Boston University School of Law Scholarly Commons at Boston University School of Law

Faculty Scholarship

$10-31-2011$

\title{
Combating Antibiotic Resistance Through the Health Impact Fund
}

Kevin Outterson

Boston Univeristy School of Law

Thomas Pogge

Yale University

Aidan Hollis

University of Calgary

Follow this and additional works at: https://scholarship.law.bu.edu/faculty_scholarship

Part of the Health Law and Policy Commons

\section{Recommended Citation}

Kevin Outterson, Thomas Pogge \& Aidan Hollis, Combating Antibiotic Resistance Through the Health Impact Fund, No. 11-30 Boston University School of Law, Law and Economics Research Paper (2011).

Available at: https://scholarship.law.bu.edu/faculty_scholarship/390 


\section{Combating Antibiotic Resistance Through The Health Impact Fund}

\section{Kevin Outterson, Thomas Pogge \& Aidan Hollis*}

Abstract: The Health Impact Fund is an innovative financing mechanism for global drug discovery and dissemination, separating the reward for successful R\&D from the market price of the drug, also known as de-linkage. Aaron Kesselheim and Kevin Outterson have recently proposed a prize and reimbursement-based de-linkage mechanism to reimburse companies for antibiotics according to their social value, but conditioned on achieving conservation goals to limit resistance. This paper will explore whether this antibiotic resistance conservation proposal can be adapted to the framework of the Health Impact Fund. If these proposals can be meshed, then antibiotics might be an interesting therapeutic class for a test of the Health Impact Fund.

\section{Introduction}

On April 7, 2011, the World Health Organization embarked on a yearlong campaign to combat antibiotic resistance. The project is driven by several related concerns: resistance is rising, drug companies are producing fewer innovative antibiotics, and yet antibiotics continue to be used inappropriately. ${ }^{1}$ Resistance

\footnotetext{
* From Boston University (KO); Yale University (TP); and the University of Calgary (AH). Correspondence to mko@bu.edu. Aaron Kesselheim, Adrian Towse and Wendy Gordon provided helpful comments. Mark Nickas provided research assistance. 1World HEAlth ORGanization, World HEAlth DAY - 7 APRIL 2011, (available at http://www.who.int/world-health-day/2011/en/index.html.); A.D.So, N. Gupta, S.K. Brahmachari, I. Chopra, C. Nathan, K. Outterson, J.P. Paccaud, D.J. Payne, R.W. Peeling, M. Spiegelman, \& J. Weigelt,
} 
distorts markets for innovative antibiotics in unusual and counterintuitive ways, giving major stakeholders economic incentives to waste these precious resources. ${ }^{2}$ An insurance reimbursement system that rewards companies primarily for unit sales of antibiotics undermines public health goals such as the rational use of antibiotics. Conversely, rational use, infection control and anti-bacterial vaccine programs significantly reduce antibiotic sales, undermining company research and development (R\&D) incentives. ${ }^{3}$ As a result, a prominent drug industry leader recently stated that antibiotic "incentives that separate the financial return from the use of a product are the only way to change this behavior."4 Such mechanisms are called "de-linkage" in that they separate the markets for medicines from R\&D cost recovery. In de-linkage, product sales revenues are not the sole source of R\&D cost recovery and profits, but are supplemented or replaced by other mechanisms such as prizes.

Towards New Business Models for R\&D for Novel Antibiotics, 14 DRUG RESISTANCE UPDATES 88 (2011) [hereinafter Towards New Business Models]; Infectious Diseases Society of America, Combating Antimicrobial Resistance, Policy Recommendations to Save Lives, 52 CLIN. InFECT. Dis. (Supp. 5) S397 (2011).

${ }^{2}$ Towards New Business Models, supra note 1; Kevin Outterson, The Legal Ecology of Resistance: The Role of Antibiotic Resistance in Pharmaceutical Innovation, 31 CARDOZo L. REV. 613, 628 (2010) [hereinafter, Legal Ecology]; Aaron S. Kesselheim \& Kevin Outterson, Fighting Antibiotic Resistance: Marrying New Financial Incentives to Meeting Public Health Goals, 29 Health AfFaIRS 1689 (2010); Ramanan Laxminarayan \& Anup Malani, EXTENDING THE CuRE: PoliCy RESPONSES TO THE GRoWING THREAT OF ANTIBIOTIC RESISTANCE (2007) available at http://www.extendingthecure.org/report; Rachel Nugent, Emma Back \& Alexandra Beith, The RACE Against Drug Resistance (2010), available at http://www.cgdev.org/content/publications/detail/1424207/; Elias Mossialos, Chantal M. Morel, Suzanne Edwards, Julia Berenson, Marin Gemmill-Toyama \& David Brogan, Policies AND InCEnTives FOR PROMOTING INNOVATION IN ANTIBIOTIC RESEARCH (2010), available at http://www.euro.who.int/_data/assets/pdf_file/0011/120143/E94241.pdf.

${ }^{3}$ Legal Ecology, supra note 2.

${ }^{4}$ Towards New Business Models, supra note 1. 
One prominent de-linkage mechanism is the Health Impact Fund (HIF) which would reward companies for the health impact of their drugs. ${ }^{5}$ The HIF is a global mechanism, which is especially valuable in the field of antibiotics. Effective antibiotics are a global common pool, a potentially exhaustible resource that should be managed effectively on a global basis. ${ }^{6}$

This essay is organized as follows. In Section II, we describe the original Health Impact Fund proposal in greater detail, including some of the criticisms that have been lodged concerning generic competition. The legal and biological complexities of resistance are explored in Section III. The legal ecology of resistance strongly suggests that new antibiotic incentives must be conditioned on meeting long-term public health goals. Otherwise, the rush to produce new antibiotics will only hasten the arrival of resistance. The confluence of antibiotic resistance and the HIF is the subject of Section IV, evaluating whether antibiotics might be an appropriate test of the HIF and whether the HIF might be an effective global coordination mechanism for antibiotics. We conclude that antibiotics as a class may be an appropriate first application of the HIF, but that the problems of crossresistance will probably require all antibiotics to participate. Significant questions and limitations are noted.

The stakes are huge for getting these policies right; the Infectious Diseases Society of America warns that the alternative may be a global ecological collapse in

\footnotetext{
5 Aidan Hollis \& Thomas Pogge, The Health Impact Fund: Making New Medicines Accessible for All (Incentives for Global Health, 2008) available at http://www.yale.edu/macmillan/igh/hif_book.pdf. See www.healthimpactfund.org for many publications and media discussions about the HIF as well as information about HIF supporters and their work.

${ }^{6}$ Laxminarayan \& Malani, supra note 2; Nugent, Back \& Beith, supra note 2; Mossialos, et al., supra note 2 .
} 
antibiotic effectiveness. ${ }^{7}$

\section{The Health Impact Fund}

\section{A. Paying for Global Health Impact}

Financed primarily by governments, the Health Impact Fund is a proposed pay-for-performance mechanism that would offer innovators the option completely voluntary ${ }^{8}$ - to register any new medicine. ${ }^{9}$ By registering a product, the innovator would undertake to make it available, during its first 10 years on the market, wherever it is needed at no more than the lowest feasible cost of production and distribution. The innovator would further commit to allow, at no charge, generic production and distribution of the product after these ten years have ended (if the innovator still has unexpired patents on the product). In exchange, the registrant would receive, during that 10 -year period, annual reward payments based on the product's health impact. The reward payments would be part of a large annual payout, with each registered product receiving a cash payment from the HIF proportional to its share of the assessed health impact of all HIF-registered products in the relevant year. ${ }^{10}$ If the HIF were found to work well, its annual reward pool

\footnotetext{
7Infectious Diseases Society of America, supra note 1; Infectious Diseases Society of America, BAD Bugs, No Drugs: As Antibiotic Discovery Stagnates...A Public Health Crisis Brews (2004), available at http://www.idsociety.org/uploadedFiles/IDSA/Policy_and_Advocacy/Current_Topics_and_Issues/A dvancing_Product_Research_and_Development/Bad_Bugs_No_Drugs/Statements/As\%20Antibiotic\% 20Discovery $\% 20$ Stagnates $\% 20 \mathrm{~A} \% 20$ Public $\% 20$ Health $\% 20$ Crisis $\% 20$ Brews.pdf\#search= $\% 22 \mathrm{BAD}$ BUGS NO DRUGS\%22 [hereinafter, BAD BUGS, No DRUGS].

${ }^{8}$ As noted below, the problem of cross-resistance might require antibiotics to join the HIF in an all-ornothing system.

${ }^{9}$ Under certain conditions, the HIF might also permit a company to register a traditional medicine or a new use of an existing medicine.

${ }^{10}$ In some cases, the HIF may want to create contractual minimum and maximum payout amounts to reduce uncertainty for registrants.
} 
could be scaled up to attract an increasing share of new medicines. ${ }^{11}$

The HIF would foster the development of new high-impact medicines including against diseases concentrated among the poor that are now neglected because innovators cannot recover their R\&D costs from sales to the poor..$^{12}$ The option of an alternative reward based on health impact would transform heretoforeneglected diseases into some of the most lucrative pharmaceutical R\&D opportunities. For example, many have suggested that antibiotic research isn't financially rewarding for large pharmaceutical companies. ${ }^{13}$ The HIF would help to reverse that problem by offering an alternative revenue stream of up to several billion dollars per drug over the ten-year registration period.

The HIF would also promote appropriate financial access to new medicines by contractually limiting the price of any registered product to the lowest feasible cost of production and distribution. In addition, since the HIF only pays for actual health impact, the companies themselves are economically motivated to maximize access. The HIF rewards drug company registrants when their products are appropriately available to the neediest patients, perhaps at prices below marginal cost, and that they are competently prescribed and optimally used. Registrants would be rewarded not for selling their products, but for making them effective toward improving global health. For antibiotics, health impact will be maximized not necessarily through aggressive sales, but also through careful long-term

\footnotetext{
${ }^{11}$ Hollis \& Pogge, supra note 5.

${ }^{12}$ The HIF is limited to new medicines, and perhaps new uses for existing molecules. It does not directly change incentives for existing generic drugs, but if HIF-registered drugs are fully deployed, they may effectively compete with generic drugs at lower prices.

13 Towards New Business Models, supra note 2.
} 
stewardship and appropriate use. HIF incentives would need calibration to the unique characteristics of antibiotics.

If some pharmaceutical R\&D were financed through tax-funded HIF rewards, most of the cost would be borne by affluent populations and people - just like today. But there are important differences. First, innovators would make no profit from the sale of their medicine as such - they would profit only insofar as this medicine is actually used to improve patient health. Second, in order to profit from serving affluent patients, innovators would not need to exclude poor patients. On the contrary, they would profit equally from serving poor patients, too, even if the drugs were offered at very low prices. Health gains achieved for any patients — rich or poor - would contribute equally toward the innovator's bottom line.

The HIF will provide optimal incentives only if potential registrants are assured that the rewards will actually be there in the decade following market approval. Core funding of the HIF is therefore best guaranteed by a broad partnership of countries. If governments representing one third of global income agreed to contribute just 0.03 percent of their gross national incomes ( 3 of every 10,000 currency units), the HIF could get started with USD 6 billion annually. This fixed pool of funds will be divided annually among registrants in proportion to the health impact of the registered drug. Thus, the HIF can be seen as an ongoing competition among innovators that ranges over all countries and all diseases, with firms earning more money if their product has a larger impact on health.

Health impact can be measured in terms of the number of quality-adjusted 
life years (QALYs) ${ }^{14}$ saved worldwide. The QALY metric is already extensively used by private and state insurers in determining prices for new drugs, so employing it in calculating HIF rewards is not a big leap. Taking as a benchmark the pharmaceutical arsenal before a registered medicine was introduced, the HIF would estimate to what extent this medicine has added to the length and quality of human lives. This estimate would be based on surveillance data, clinical trials, including pragmatic trials in real-life settings, combined with data on sales volumes and the demographic and clinical characteristics of patients using the product. Additional tools that could be used include tracking randomly selected medicines (identifiable by serial numbers) to their end users, and statistical analysis of sales data as correlated with data about the global burden of disease. These estimates would necessarily be imperfect. But so long as any errors are random and small, or at least not exploitable by registrants, ${ }^{15}$ HIF incentives would be would remain correct in their direction and relative sizes.

The reward rate, in terms of dollars per QALY, would be calculated annually for each registered drug in the HIF. This rate would vary, depending on the total number of QALYs in the HIF for a given year. With the HIF so designed, innovators would choose to register products that can reduce the global burden of disease most cost-effectively. Products with the largest health impact would make the most money - creating exactly the right incentives for innovation. And because the HIF would be an optional system, the reward rate is self-adjusting. If rewards were too

\footnotetext{
${ }^{14}$ For additional details on using QALYs to measure health impact, see Hollis \& Pogge, supra note 5.

${ }^{15}$ Since registrants are competing for shares of a fixed pool, public monitoring will be supplemented by the private monitoring efforts of other firms in the HIF.
} 
high, new registrants would enter and reduce the annual reward rate (money per QALY). If profits were too low, the reward rate would naturally increase as firms would choose, for more of their new products, to forego HIF registration in favor of exploiting the ordinary patent-based marketing system. Competition would ensure that registered products are rewarded at a rate that is profitable for innovators and maximizes the effect of the HIF.

To be certain that the HIF is cost-effective relative to other public health expenditures, one can stipulate a maximum reward rate; if one year's funds are not fully used, the remainder can be rolled over into future years. To reassure potential innovators, one can also add some protection against unreasonably low rewards. ${ }^{16}$

\section{B. Advantages of the Health Impact Fund}

Let us sketch how the original HIF proposal would, without revision of the TRIPS Agreement, ${ }^{17}$ provide systemic relief for seven failings of the present system.

High Prices would not exist for HIF-registered medicines. In local markets where buyers were particularly price sensitive, innovators would have strong incentives to reduce prices, possibly even below the cost of production, in order to increase health impact rewards through increased volume.

Diseases Concentrated among the Poor, insofar as they contribute substantially to the global disease burden, would no longer be neglected. In fact, the more destructive among them would come to afford some of the most lucrative

16 Hollis \& Pogge, supra note 5.

${ }^{17}$ The TRIPS Agreement sets global minimum standards for intellectual property law. 
research opportunities for biotechnology and pharmaceutical companies. The HIF counts health benefits to the poorest of patients equally with health benefits to the richest.

Bias toward Maintenance Drugs ${ }^{18}$ would be absent from HIF-encouraged research. The HIF assesses each registered medicine's health impact in terms of how its use reduces mortality and morbidity worldwide-without regard to whether it achieves this reduction through cure, chronic treatment, or prevention. This would guide firms to deliberate about potential research projects in a way that is also optimal for global public health, namely in terms of the expected global health impact of the new medicine relative to the cost of developing it. The profitability of research projects would be aligned with their value in terms of global public health.

Wastefulness would be dramatically lower for HIF-registered products. There would be no deadweight losses from large mark-ups. ${ }^{19}$ There would be less costly patent litigation as generic competitors would lack incentives to invalidate weak patents and innovators would have less incentive to suppress generic products (as these would enhance the innovator's health impact reward). Innovators might therefore often not even bother to obtain, police, and defend patents in many

\footnotetext{
${ }^{18}$ Drugs for long-term chronic conditions may be sold to the same patients for many years, which provides a longer and more stable market. By contrast, an antibiotic is generally given only for a short course and a vaccine is generally delivered in a single dose. Drug company executives complain that the market is therefore biased in favor of maintenance drugs. See, e.g., Steven J. Projan, Why is Big Pharma Getting Out of Antibacterial Drug Discovery?, 6 CURREnt OPINION IN Microbiology 427 (2003).

${ }^{19}$ Sean Flynn, Aidan Hollis, and Michael Palmedo, An Economic Justification for Open Access to Essential Medicine Patents in Developing Countries, 37 Journal of Law, Medicine \& Ethics 184 (2009).
} 
national jurisdictions. To register a medicine with the HIF, innovators need show only once that they have an effective and innovative product. ${ }^{20}$

Excessive Marketing would also be much reduced for HIF-registered medicines. Because each innovator is rewarded for the health impact of its addition to the medical arsenal, incentives to develop me-too drugs to compete with an existing HIF-registered medicine would be weak. And innovators would have incentives to urge a HIF-registered drug upon doctors and patients only insofar as such marketing results in measurable therapeutic benefits for which the innovator would then be rewarded. In antibiotics, this feature will be especially welcome, as it removes financial pressures to promote resistance through excessive sales.

Counterfeiting of HIF-registered products would be less attractive. With the genuine item widely available near or even below the marginal cost of production, there is less to be gained from producing and selling counterfeits. ${ }^{21}$

The Last-Mile Problem would be mitigated because each HIF-registered innovator would have strong incentives to ensure that patients are fully instructed and properly provisioned so that they make optimal use (dosage, compliance, etc.) of its medicines, which will then, through wide and effective deployment, have their optimal public health impact. Rather than ignore poor countries as unprofitable markets, pharmaceutical companies would, moreover, have incentives to work with one another and with national health ministries, international agencies and NGOs

\footnotetext{
20Talha Syed, Should a Prize System For Pharmaceuticals Require Patent Protection For EligibiLity? (Incentives for Global Health, Discussion Paper No. 2, 2009).

${ }^{21}$ Kevin Outterson \& Ryan Smith, Counterfeit Drugs: The Good, The Bad, and the Ugly, 16 Albany L. J. of Science \& Technology 525 (2006).
} 
toward improving the health systems of these countries in order to enhance the impact of their HIF-registered medicines there.

\section{Critiques of the Health Impact Fund}

James Love of Knowledge Ecology International has criticized the HIF in a number of forums. ${ }^{22}$ Love has proposed several global de-linkage mechanisms to pay for R\&D outside of the market reimbursement system. ${ }^{23}$ His primary substantive criticism is that the HIF leaves patents in the hands of the patent owners, thereby delaying market-based generic competition from multiple producers. Others share this concern in the broader context of prize proposals that rely on contractual access provisions. ${ }^{24}$ In response to these criticisms, the HIF proposal was adjusted to permit: (a) sub-contracting (licensing) to generic firms; (b) tender systems; and (c) administratively determined prices. ${ }^{25}$ The final form of

\footnotetext{
${ }^{22}$ See James Love, The HeALTH ImPACT Fund PROPOSAL, (Knowledge Ecology International, 2008), available at http://keionline.org/hif. For a recent response from the HIF project, see Thomas Pogge \& Jake Hirsch-Allen, A Response From the Authors of the Health Impact Fund, Intellectual Property Watch, Oct. 3, 2011, available at http://www.ip-watch.org/weblog/2011/10/03/a-response-fromthe-authors-of-the-health-impact-fund/.

23James Love, Prizes, Not Prices, to Stimulate Antibiotic R\&D, SCI. \& Develop. Network, Mar. 26, 2008, available at http://www.scidev.net/en/opinions/prizes-not-prices-to-stimulate-antibiotic-r-d-.html; James Love \& Tim Hubbard, The Big Idea: Prizes to Stimulate R\&D for New Medicines, 82 CHI.-Kent L. REv. 1519 (2007); James Love \& Tim Hubbard, Prizes for Innovation of New Medicines and Vaccines, 18 ANNALS HEALTH L. 155, 159-60 (2009).

${ }^{24}$ Paul Wilson \& Amrita Palriwala, Prizes for Global Health Technologies: An Assessment with a CASE STUDY IN TB DiAGNOSTICS (2010), available at http://healthresearchpolicy.org/sites/healthresearchpolicy.org/files/assessments/files/R4D\%20Pri zes\%20Assessment\%20Draft\%20Report_2.pdf; Donald W. Light, Making Practical Markets for Vaccines, 2 PLOS MEd. 934 (2005); Donald W. Light, Is G8 Putting Profits Before the World's Poorest Children?, 370 LANCET 297 (2007); Donald W. Light, GAVI's Advance Market Commitment, 375 LANCET 638 (2010).

25 Aidan Hollis, The Health Impact Fund And Price Determination (Incentives for Global Health Discussion Paper \#1, 2009) available at http://www.yale.edu/macmillan/igh/files/papers/DP1_Hollis.pdf).
} 
the HIF has yet to be determined and it is likely that a variety of contract options may prove most attractive for different classes of medicines. With respect to antibiotics, because of the interest in conservation, there is a stronger rationale to prefer to limit the rights to produce and sell the drug, as we explore below.

Other practical concerns include measuring health impact in order to determine the prize payments and obtaining sufficient financial support to fund the HIF. Measurement will be a complex task, with many real-world epidemiological problems to solve, including tracking and disentangling the various causal factors implicated in health impact. Substantial work is underway to articulate appropriate metrics, but will not be detailed here, as it was the subject of a two-day conference at Harvard in November 2009 and ongoing work thereafter. In addition to measuring the health impact from antibiotics in a specific year, additional work is needed to consider the future health impact of inappropriate antibiotic use today.

The funding question will be dependent upon the political will to initiate a realistic test of the HIF. This essay outlines a therapeutic category of drugs for a potential large-scale test, namely systemic antibacterials.

\section{The Legal Ecology of Antibiotic Resistance and the Need for Global Coordination}

Before turning to the potential case of an antibiotic HIF (aHIF), we must briefly explore some of the unique legal and biological aspects of antibiotics. These unique characteristics make antibiotics an appealing candidate for a test of the HIF, but also suggest some aHIF modifications to account for the problem of resistance. 
Antibiotics may be the greatest single medical success of the twentieth century. If antibiotics were to lose their effectiveness, some of the advances in health over the previous seventy-five years would be threatened. The edifice of modern medicine rests upon the foundation of effective antibiotic therapies. But this achievement rests on an insecure foundation. As antibiotics are used, they create evolutionary pressure that threatens their undoing through resistance. ${ }^{26}$ Resistance is an evolutionary dynamic.

Antibiotic effectiveness can also be understood as an ecological issue, a valuable common pool resource akin to productive fisheries. Common pools are prone to depletion and collapse through uncoordinated withdrawals, which is the history of the destruction of the vast herds of American buffalo in the Great Plains in the $19^{\text {th }}$ Century. ${ }^{27}$ In the case of antibiotics, withdrawals occur as antibiotic resistance grows through use and misuse, including antibiotic pollution when resistance externalities are spread across populations and drugs. The common pool is renewed through conservation and the addition of new antibiotic therapies. We face a tragedy of the antibiotic commons as uncoordinated use, misuse and pollution of precious antibiotics may prematurely destroy these important drugs. ${ }^{28}$ Incentives for new antibiotics must therefore be conditioned on addressing both

\footnotetext{
26 BAD Bugs, No DRUGS, supra note 7; Infectious Diseases Society of America, supra note 1; Mossialos et al., supra note 2; Nugent, Back \& Beith, supra note 2; Laxminarayan \& Malani, supra note 2.

27 M. Scott Taylor, Buffalo Hunt: International Trade and the Virtual Extinction of the North American Bison, AMER. ECON. REV. (forthcoming 2011).

${ }^{28}$ Timo Goeschl \& Timothy Swanson, The Interaction of Dynamic Problems and Dynamic Policies: Some Economics of Biotechnology, in BATTLING RESISTANCE TO ANTIBIOTICS AND PESTICIDES: AN ECONOMIC APPROACH (Ramanan Laxminarayan ed., 2003); Kevin Outterson, The Vanishing Public Domain: Antibiotic Resistance, Pharmaceutical Innovation and Intellectual Property Law, 67 U. PITT. L. REV. 67, 122 (2005) [hereinafter, Vanishing Public Domain].
} 
ecological and evolutionary (Eco/Evo) factors, ${ }^{29}$ to ensure that long-term public health goals are achieved. ${ }^{30}$

Resistance creates at least six important policy issues for antibiotic incentives, as described in the chart below and the text that follows:

\begin{tabular}{|l|l|}
\hline Policy Issue & Implications \\
\hline $\begin{array}{l}\text { 1. Conservation dampens R\&D } \\
\text { incentives for new antibiotics }\end{array}$ & $\begin{array}{l}\text { Optimal solutions must balance } \\
\text { conservation and new production; faster } \\
\text { introduction of new molecules may harm } \\
\text { global public health }\end{array}$ \\
\hline $\begin{array}{l}\text { 2. Companies have financial } \\
\text { incentives to maximize unit sales of } \\
\text { antibiotics, wasting antibiotics } \\
\text { through resistance }\end{array}$ & $\begin{array}{l}\text { De-linkage enables companies to profit } \\
\text { from meeting public health goals }\end{array}$ \\
\hline $\begin{array}{l}\text { 3. Resistance stimulates innovation } \\
\text { by clearing the field of competitive } \\
\text { antibiotics }\end{array}$ & $\begin{array}{l}\text { New antibiotic molecules should be well } \\
\text { timed, arriving when needed due to } \\
\text { resistance rather than as quickly as } \\
\text { possible }\end{array}$ \\
\hline $\begin{array}{l}\text { 4. Patents are clumsy policy levers } \\
\text { for antibiotic policy because pollution } \\
\text { externalities differ in each drug-bug } \\
\text { combination }\end{array}$ & $\begin{array}{l}\text { Explore alternative de-linkage } \\
\text { mechanisms, such as reimbursement, } \\
\text { prizes and aHIF }\end{array}$ \\
\hline $\begin{array}{l}\text { 5. Resistance is a global problem } \\
\text { f. Antibiotic innovation is broken }\end{array}$ & $\begin{array}{l}\text { Solutions must be scalable across the } \\
\text { globe and cannot depend on the existence } \\
\text { of highly functional governments and } \\
\text { infrastructure in poor countries }\end{array}$ \\
\hline $\begin{array}{l}\text { Managing pollution externalities is } \\
\text { difficult and complex }\end{array}$ \\
\hline
\end{tabular}

The first is the effect of conservation upon incentives for $R \& D$ of new

\footnotetext{
${ }^{29}$ Fernando Baquero, Teresa M. Coque, Fernando de la Cruz, Ecology and Evolution as Targets: the Need for Novel Eco-Evo Drugs and Strategies To Fight Antibiotic Resistance, 55 AnTIMICROBIAL AGENTS AND CHEMOTHERAPY 3649-60 (2011) ("Classical measures trying to contain or slow locally the progress of antibiotic resistance in patients on the basis of better antibiotic prescribing policies have clearly become insufficient at the global level. Urgent measures are needed to directly confront the processes influencing antibiotic resistance pollution in the microbiosphere. Recent interdisciplinary research indicates that new eco-evo drugs and strategies, which take ecology and evolution into account, have a promising role in resistance prevention, decontamination, and the eventual restoration of antibiotic susceptibility.")

${ }^{30}$ Kesselheim \& Outterson, supra note 2.
} 
antibiotics. ${ }^{31}$ Both conservation and R\&D are laudable, but in many ways conservation and R\&D work at cross-purposes, and difficult choices must be made between them. For example, insofar as antibiotic conservation is successful in curbing inappropriate use and maintaining the effectiveness of existing products, it will suppress demand for new antibiotics. Viewed from the dynamic perspective of R\&D into new drugs, conservation programs undercut market incentives by dampening future demand. ${ }^{32}$ But from the static perspective of public health, conservation is an unqualified success when infections are prevented or antibiotic resistance averted. In an optimally coordinated market, current antibiotics would be conserved for as long as possible and new ones introduced on a "just in time" basis, perhaps with some antibiotics held in a Strategic Antibiotic Reserve for emergencies. ${ }^{33}$ This sort of coordination is terribly difficult at present, but might be a key advantage of the aHIF.

The second problem is the financial incentives that the market gives to drug companies, hospitals, physicians, pharmacists and informal health care workers around the globe. ${ }^{34}$ All of these parties are rewarded by moving product, especially through increased unit sales of antibiotics. A sale yields the same profit whether the use is actually appropriate or not. In ordinary drugs, this situation is wasteful if money is spent unnecessarily or dangerous if patients are needlessly exposed to pharmaceutical risks. With antibiotics, the damage of inappropriate use is

\footnotetext{
${ }^{31}$ Legal Ecology, supra note 2, at 628.

${ }^{32}$ Id.

${ }^{33}$ Kesselheim \& Outterson, supra note 2.

${ }^{34}$ Towards New Business Models, supra note 2; Kesselheim \& Outterson, supra note 2; Aaron S. Kesselheim \& Kevin Outterson, Improving Antibiotic Markets for Long Term Sustainability, 11 YALE J. HEALTH Pol'Y, L. \& ETHICS 101, 155 (2011) [hereinafter, Improving Antibiotic Markets].
} 
multiplied because misuse promotes resistance, destroying the power of the drug for future patients as well.

Companies also sell antibiotics for animal use. Most US antibiotic sales (by volume) are for use in healthy animals, which raises the potential of resistant organisms developing in animal hosts. Restricting such sales might promote human health, but would lower profits for drug companies and raise costs for some farmers. The aHIF would give companies an incentive to limit nontherapeutic agricultural uses, saving antibiotics for human use.

Patent systems recover R\&D costs through pricing above marginal cost. Firms will have incentives to exploit their patent through over-producing (relative to the social optimum) during the exclusivity period. Nor is it clear that society would be well served by pricing at marginal cost: unlike many drugs with deadweight losses due to lost sales, overuse of antibiotics could be welfare-reducing due to resistance. The aHIF could rationalize these incentives by paying for health impact, not just product sales.

The third quandary is the relationship between resistance and innovation. The conventional wisdom assumes that resistance is a problem in antibiotic innovation, but resistance may also stimulate innovation..$^{35}$ In other drug classes, new entrants must compete against generic drugs with proven records of safety and efficacy. Lipitor (atorvastatin) is an excellent statin, and when it transitions to fully generic status, atorvastatin will set a high bar against which new statin drugs must be measured. Importantly, the use of atorvastatin by one person does not

35 Projan, supra note 18; Towards New Business Models, supra note 2; Legal Ecology, supra note 2, at 637. 
undermine its value for any other person: the billionth dose is just as effective as the first. None of this is true for antibiotics. Penicillin was an outstanding antibiotic, perhaps better than almost anything we have seen in many decades. But resistance makes highly effective antibiotics obsolete over time, which clears the competitive field before a new drug enters the market. This trend of declining effectiveness favors entry of new antibiotic molecules. Paradoxically, speeding market entry of antibiotics may actually accelerate resistance, by flooding the market with competing drugs that trigger another round of resistance. ${ }^{36}$ The aHIF would reward well-timed antibiotic introductions, which arrive to address the greatest human health needs.

The fourth issue concerns the policy levers employed in the battle against antibiotic resistance. Prior scholarship has been perhaps too quick to turn to patent law as the preferred policy lever. For example, the Infectious Diseases Society of America (IDSA) has catalogued the thin pipeline of new antibiotic therapies, but called for significant changes in patent law to remedy the problem, including patent extensions and wildcard patent extensions for antibiotics. ${ }^{37}$ In our view, patent law mechanisms are ill suited to address the resistance problem, in part because patent law is not flexible enough to be carefully calibrated to the biological complexity of resistance. ${ }^{38}$ The traditional advantage of patent law is its reliance on market pricing, but many pharmaceutical prices are not really set by the market, but are governed by public reimbursement systems. In effect, elements of the

\footnotetext{
${ }^{36}$ Legal Ecology, supra note 2, at 637.

37 BAD Bugs, No DRUGS, supra note 7; Infectious Diseases Society of America, supra note 1.

38 Vanishing Public Domain, supra note 28; Improving Antibiotic Markets, supra note 34.
} 
pharmaceutical market are already de-linked, but not in a system that prioritizes global health impact. ${ }^{39}$ To the extent that market-based pricing is an important element of the patent system, its absence in pharmaceuticals is quite troubling. If the primary market signals are muddled or broken, additional modifications to patent law should not be rolled out before the reimbursement system is fixed. ${ }^{40}$ The aHIF side steps these problems by creating a new de-linkage mechanism to focus reimbursement on the most socially desirable pharmaceutical innovations.

Resistance spreads globally across political and geographic boundaries, giving rise to our fifth policy concern: antibiotic resistance is an ecological pollution problem that requires global coordination mechanisms that are not currently being provided by the market. Global coordination through the WHO is poorly funded and focused on conservation. Global coordination through the patent system is unhelpfully devoted to selling new drugs. As described above, conservation and new drug R\&D incentives work at cross-purposes. By paying for human health impact anywhere on the planet, the aHIF would be uniquely well placed to globally coordinate these issues.

Finally, the antibiotic innovation system is not functioning well. Compare antibiotic innovation with information technology: what if successive generations of laptops were larger and slower with diminished capabilities? Or suffered incremental safety problems with each new model? No one would consider that situation acceptable for laptop innovation, and yet that is the landscape for antibiotics. Today's antibiotics are in many ways inferior to the drugs available in

${ }^{39}$ Kesselheim \& Outterson, supra note 2.

40 Id. 
1950; most of the antibiotics approved in the "glory days" of the 1980s were subsequently withdrawn from the market, many with safety problems ${ }^{41}$ Antibiotics suffer from an innovation deficit.

But a significant increase in antibiotic drug approvals may not solve the problem. ${ }^{42}$ Companies are rewarded based on antibiotic unit sales, and often focus on the wrong types of innovation. In many antibiotic drugs, resistance can be transmitted within the antibiotic drug class to other drugs in the class, permitting market rivals to pollute on their competitors' drugs. These resistance patterns can vary between different bacterial species. In this ecological context, bringing additional "me-too" drugs to market within an existing class can speed the destruction of all drugs in the class. Cross-class resistance complicates the problem even more, as the pollution affects more distant drugs. ${ }^{43}$ A patent race that results in too many molecules reaching the market at the same time is not success, but failure. Multiple simultaneous entries of antibiotics with pollution externalities should be considered uncoordinated withdrawals by competitors from a potentially exhaustible common pool. ${ }^{44}$ Such races may drive resistance instead of improving human health.

Antibiotic pollution externalities could potentially be managed by Coasian contractual mechanisms between companies producing antibiotics. The number of patent-owning firms involved is relatively small, but cooperation in this fashion

\footnotetext{
41Enrique Seoane-Vazquez, Jing Hao, \& Rosa Rodriguez-Monguio, Exploring the Relationship Between Drug Patent Life and Drug Approvals, (abstract), American Public Health Association (2011) (available at http://apha.confex.com/apha/139am/webprogram/Paper246364.html).

42 Kevin Outterson, John H. Powers, Ian M. Gould, \& Aaron S. Kesselheim, Questions About the 10 x'20 Initiative, 51 CLIN. INFECT. DIS. 751 (2010).

43 Vanishing Public Domain, supra note 28; Improving Antibiotic Markets, supra note 34.

${ }^{44}$ Laxminarayan \& Malani, supra note 2.
} 
would run afoul of the antitrust statutes in the US and competition laws around the world. As a result, limited antitrust waivers would be required for any coordinating mechanism between the companies. ${ }^{45}$ But antibiotic pollution also affects society at large, greatly increasing the number of persons involved. Once the patent expires, the number of polluting firms can increase significantly. Finally, antibiotic pollution externalities vary significantly depending on how the antibiotic is used, making the contractual solution even more difficult to manage.

A related problem involves truly innovative antibiotics, especially drugs with entirely new mechanisms of action. These antibiotics are the first entrant into a new "functional resistance group." 46 To the extent that competitors' actions don't damage the new drug, then the patent owner need not fear obsolescence through resistance pollution. But the patent clock ticks on, since the company owns a timelimited property right. The company has every incentive to bring this molecule to market quickly, even absent either urgent clinical need or pollution risk. This market introduction begins the countdown to resistance for a new functional resistance group of antibiotics. In short, the patent holder has strong financial incentives to waste the antibiotic, even if clinically appropriate alternatives exist. ${ }^{47}$ For these first-in-class antibiotics, society would be better served by keeping these drugs off the market until clinically necessary. One potential solution is the Strategic Antibiotic Reserve (Reserve), which would pay patent owners handsomely to entirely forgo marketing the drug class until the day that resistance to other

45 Improving Antibiotic Markets, supra note 34, at 112.

${ }^{46}$ Laxminarayan \& Malani, supra note 2.

47 Vanishing Public Domain, supra note 38, at 103-4. 
drugs necessitated a withdrawal from the Reserve. ${ }^{48}$ The analogy is to the strategic petroleum reserve, saving an exhaustible resource for a day of utmost need. The Reserve is distinguished from the aHIF in that it pays for not using a drug, based on estimated future health impact. The Reserve and the aHIF are complementary but distinct proposals.

\section{The Antibiotic Health Impact Fund (aHIF)}

In the following pages, we explore first the details of how the aHIF would impact R\&D incentives for antibiotics, before turning to the issue of conservation. In both cases, the aHIF may be able to solve vexing problems in this sector, serving as a global coordinating mechanism to simultaneously promote appropriate use as well as boosting incentives for bringing important new antibiotics to market at the right time. The aHIF could encompass all systemic antibacterials for human use, or it could be more narrowly focused on antibiotics for hospital use, where the resistance problems are greatest and the potential for conservation gains more readily attainable.

\section{A. The aHIF as a global coordination mechanism for new antibiotic development}

The aHIF is very appealing as a global coordination mechanism for antibiotic R\&D. For the first time, companies would be rewarded for producing antibiotics that were better than existing therapies, with the target being actual improvement

\footnotetext{
${ }^{48}$ Kesselheim \& Outterson, supra note 2; Improving Antibiotic Markets, supra note 34, at 160-61.
} 
in human health as opposed to mere growth in unit sales. The aHIF would not function as a bureaucratic expert panel picking "winning" research programs. Companies would continue to evaluate and prioritize their own research programs, but the aHIF reward will be proportional to the health impact rather than the ability to generate sales in high-income countries through aggressive marketing. The aHIF would offer little or no reward to a company for switching patients from an older but still effective antibiotic to its own, brand-new, aHIF-registered product because the incremental health impact would be slight. Under aHIF, the new market entrant does not appropriate the entire profit the other company derived from its existing sales, but only gets rewarded if and insofar as the switch is beneficial to patients' health. New antibiotics will receive aHIF rewards only to the extent it addresses an unmet need in human health, which dramatically re-orients antibiotic R\&D goals in a socially desirable way.

The HIF has been initially scaled in the range of US\$6 billion per year over 10 years. While US\$6 billion is a relatively small percentage of global pharmaceutical sales, the aHIF would have a much more salient impact within the antibiotic class of drugs. US sales of systemic antibacterial drugs were US $\$ 11.2$ billion in $2008 ;{ }^{49}$ global sales were approximately US $\$ 42$ billion in $2009.5^{50}$ If additional focus was desired, the aHIF could be limited at first to antibiotics for hospital use, which is where the most serious resistance and infection issues are located. The aHIF would dramatically boost innovation incentives in this drug class, and serve an important

\footnotetext{
${ }^{49}$ IMS Midas (2010), IMS Health, Inc. (available at http://www.imshealth.com). Sales at exmanufacturer prices (=manufacturer invoice). Includes rebates and certain discounts. Sales at consumer prices would include wholesaler cost and pharmacy fees.

50 Bashar Hamad, The Antibiotics Market, 9 Nature Reviews Drug Discovery 675, 675-76 (2010).
} 
coordinating function by steering the work towards antibiotics with the greatest potential global health impact. Investing US\$6 billion per year in this fashion would likely be very efficient, since the social value of the unmet need for antibiotics is at least an order of magnitude higher. ${ }^{51}$

\section{B. The aHIF as a coordination mechanism for global antibiotic conservation}

The current global pharmaceutical market balances access and innovation primarily upon the fulcrum of generic entry. The global rollout of low-cost antiretroviral medicines was made possible by entry of generics. ${ }^{52}$ Access to many medicines improves after generic entry, due to the significant price reductions driven by generic competition. On a static level, deadweight loss is reduced through marginal cost production and generic distribution as soon as possible. A persistent criticism of the HIF raises the question of inadequate incentives for generic production. ${ }^{53}$ Whatever traction this criticism may or may not have in general, the calculus is different for antibiotics. For antibiotics, paradoxically, maximizing production and access may be globally counterproductive. ${ }^{54}$ Policymakers should avoid indiscriminately flooding the market with vast quantities of low-priced generic antibiotics. Inappropriate use must be restricted through antibiotic

\footnotetext{
51 Kesselheim \& Outterson, supra note 2.

52 JAMEs LOVE, Cost BenEFIT ANALYSIS FOR UNITAID PATENT POOL (2008), http://www.keionline.org/misc-docs/1/cost_benefit_UNITAID_patent_pool.pdf.

53 See Love, supra note 22.

${ }^{54}$ Much empirical work is needed to fully understand this dynamic. If significant human health needs are currently unmet due to inadequate access to existing antibiotics, widespread generic access could improve human health. On the other hand, if antibiotics are already widely misused for inappropriate conditions, increased generic access could accelerate resistance without offsetting benefits to human health. One ancillary benefit to the aHIF would be the collection and dissemination of surveillance data on these issues.
} 
conservation if long-term human health is to be maximized. As a result, concerns about generic access are uniquely less salient for the aHIF.

If we focus solely on producing new antibiotics to the exclusion of long-term conservation, then all we have done is to accelerate the final ecological collapse of every functional resistance group of antibiotics. Consider the following two charts. The first is the oft-repeated chart on the decline in FDA approvals for antibiotics over the previous decades: ${ }^{55}$

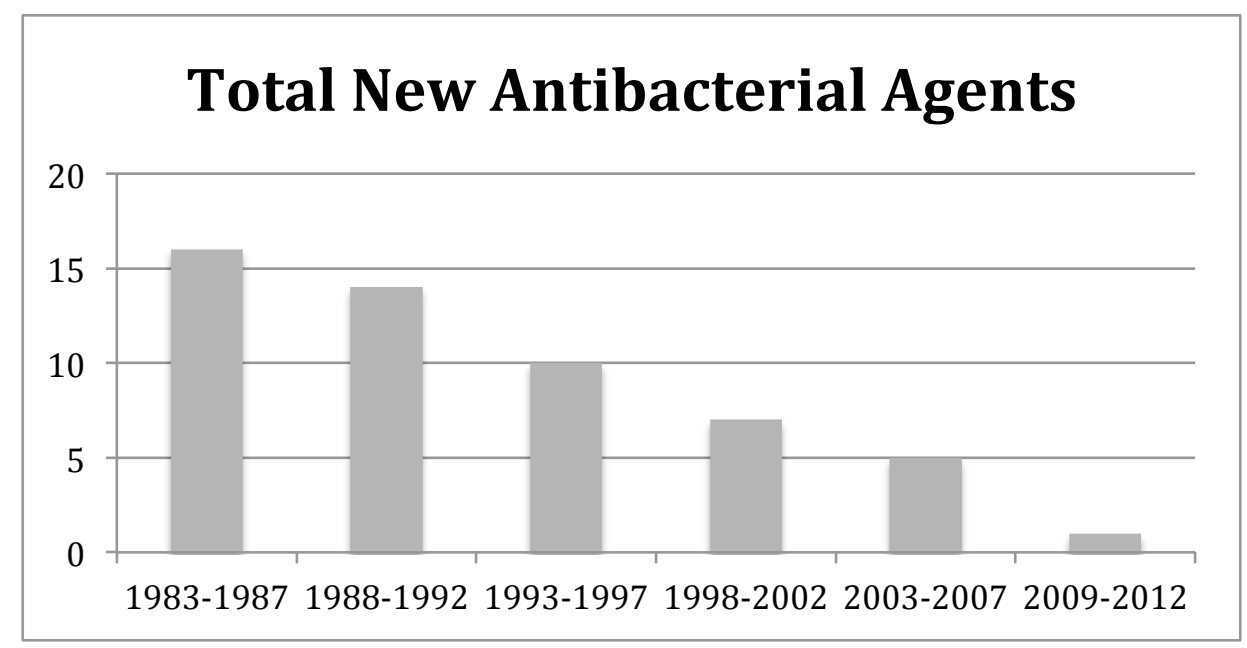

This decline might actually be a hopeful sign since antibiotics must be managed for long-term ecological and evolutionary balance, but the IDSA uses this chart to ask Congress for additional financial and patent incentives to spur production of new antibiotics. ${ }^{56}$ Conservation efforts are included in this proposed legislation, but the new financial incentives are not conditioned on meeting conservation goals. The

\footnotetext{
${ }^{55}$ Modified from BAD Bugs, No DRUGS, supra note 7.

${ }^{56}$ Antibiotic Resistance: Promoting Critically Needed Antibiotic Research and Development and Appropriate Use ("Stewardship") of These Precious Drugs, Before the H. Comm. on Energy and Commerce Subcomm. on Health, 111th Cong. (2010) (statement of Brad Spellberg, Infectious Diseases Society of America).
} 
failure to view antibiotic resistance as an ecological problem can lead to grave errors. Consider the second chart, historical data on a previous ecological collapse, the near-extermination of the North American buffalo herds in the $1870 \mathrm{~s}^{57}$

Figure 3: Implied Buffalo Hide Imports into the U.K.

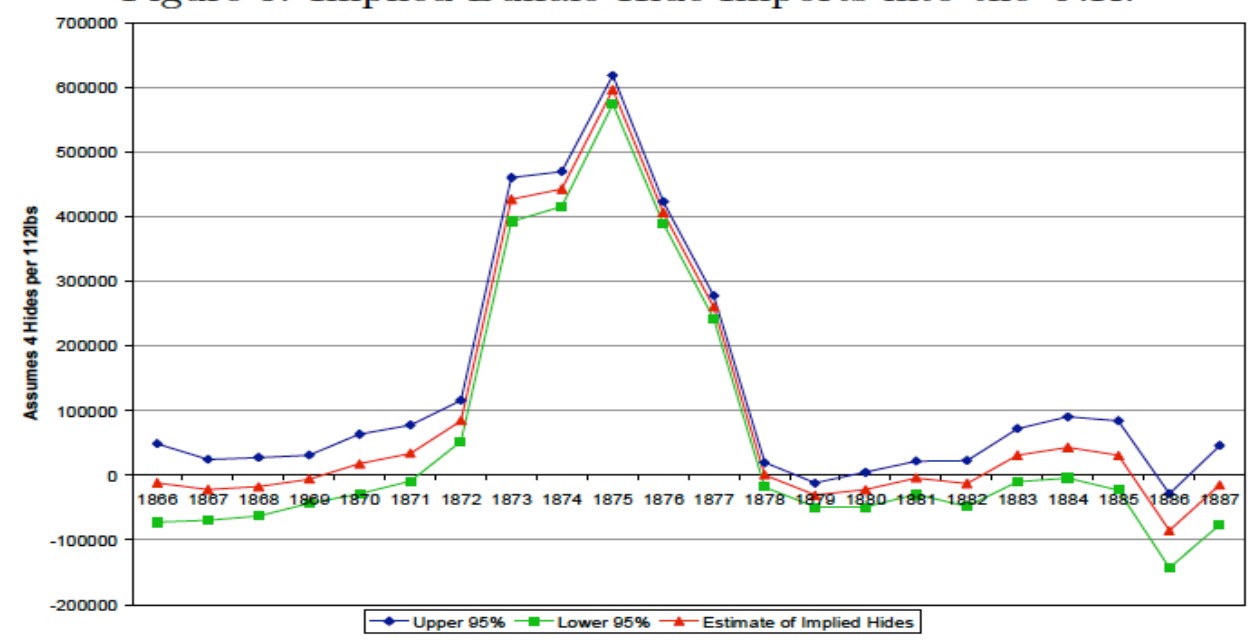

Confronted with this buffalo hide export data, the rational response in 1877 should be to stop hunting buffalo. It would have been a grave error if Congress had increased financial incentives for hunting. The buffalo population was a common pool resource that suffered ecological collapse through unsustainable withdrawals following a post-Civil War innovation in tanning techniques. Prices stayed high and the profitability of exploiting the herd was maintained - because of the large export market for hides in Europe. ${ }^{58}$ This led to the wholesale slaughter of the buffalo population in about a decade.

Any analogy between antibiotics and buffalo markets should be approached with caution. However, the common pool problems are similar. Both common

\footnotetext{
57 Taylor, supra note 27.

58 Id. Other economists focus on the late arrival of property rights as a factor in the near extermination of the herd. Dean Lueck, The Extermination and Conservation of the American Bison, 31 J. Legal Stud. 609, 638-39 (2002).
} 
pools are potentially expandable through breeding (for buffalo) and new drug introductions (for antibiotics), and can be depleted through uncoordinated withdrawals (buffalo hunting or antibiotic pollution). If private benefits from the use of polluting antibiotics are perceived to be high, but private cost are kept very low, we can anticipate many withdrawals (antibiotic use), leading to the onset of resistance unless the common pool resource is managed for long-term sustainability. Put another way, we must understand global antibiotic policy as a primarily ecological and evolutionary management question. ${ }^{59}$ The battle against microbes cannot be "won." Indeed, microbes are a significant percentage of our body weight and cellular census, with complex effects on health. The long-term goal is a sustainable balance between microbes and humanity.

In the HIF, long-term sustainability could be addressed by making additional rewards available to the extent that long-term antibiotic conservation goals are achieved. Conservation is the second major feature of our proposal, after de-linkage. Conservation rewards are the mechanism for global antibiotic coordination through the HIF.

The HIF will require the assistance of public health experts to develop appropriate antibiotic conservation goals. Outterson and Kesselheim have described one possible model, which would focus on surveillance data of actual resistance levels as the key metric. Governments would set the conservation targets, but leave implementation to the companies themselves, perhaps in

\footnotetext{
${ }^{59}$ Baquero, supra note 29.
} 
partnership with governments and appropriate non-governmental organizations. ${ }^{60}$

The defining feature of this model is the reluctance to use government to specify detailed regulations, assuming that the companies and NGOs have important information about the contours of the antibiotic markets and the heterogeneous policy tools available to reduce inappropriate use. While other models are certainly possible, reliance on the companies, in partnership with governments and NGOs, while holding the companies accountable for actual resistance targets, yields several interesting implications. The following chart summarizes these issues, which are then discussed in more detail in the text:

The aHIF as a Coordination Mechanism for Global Antibiotic Conservation.

\begin{tabular}{|c|c|c|}
\hline $\begin{array}{l}\text { Conservation incentives } \\
\text { to companies }\end{array}$ & $\begin{array}{l}\text { Examples of company } \\
\text { implementation }\end{array}$ & $\begin{array}{l}\text { Challenges for the aHIF } \\
\text { approach }\end{array}$ \\
\hline $\begin{array}{l}\text { 1. Manage their antibiotics } \\
\text { to maximize health } \\
\text { impact without } \\
\text { exceeding specific } \\
\text { resistance targets }\end{array}$ & $\begin{array}{l}\text { Cease sales of animal } \\
\text { antibiotics for non- } \\
\text { therapeutic uses; companies } \\
\text { can focus their considerable } \\
\text { marketing and government } \\
\text { relations functions on } \\
\text { appropriate use }\end{array}$ & $\begin{array}{l}\text { Relies primarily on the } \\
\text { companies to lead the } \\
\text { process after governments } \\
\text { have set the aHIF } \\
\text { conservation targets }\end{array}$ \\
\hline $\begin{array}{l}\text { 2. Coordinate activities } \\
\text { across companies to } \\
\text { minimize pollution }\end{array}$ & $\begin{array}{l}\text { Contractual agreements to } \\
\text { minimize pollution; joint } \\
\text { support for conservation } \\
\text { programs, infection control } \\
\text { and vaccines }\end{array}$ & $\begin{array}{l}\text { Requires waivers to } \\
\text { antitrust law; potential } \\
\text { spillovers of anticompetitive } \\
\text { behavior; all-or-nothing } \\
\text { aHIF might be necessary }\end{array}$ \\
\hline $\begin{array}{l}\text { 3. Manage antibiotics for } \\
\text { longer time horizons }\end{array}$ & $\begin{array}{l}\text { aHIF contracts might need to } \\
\text { be significantly longer than } \\
\text { the patent term, tied more to } \\
\text { clinical realities rather than } \\
\text { patent life }\end{array}$ & $\begin{array}{l}\text { Delays generic entry; longer } \\
\text { aHIF registration periods } \\
\text { might be necessary }\end{array}$ \\
\hline $\begin{array}{l}\text { 4. Solving "last mile" } \\
\text { problems }\end{array}$ & $\begin{array}{l}\text { Subsidize rapid point-of-care } \\
\text { diagnostics that limit unit } \\
\text { sales to appropriate use; } \\
\text { support (rather than } \\
\text { oppose) hospital formulary } \\
\text { restrictions that support } \\
\text { appropriate use }\end{array}$ & $\begin{array}{l}\text { Companies control this } \\
\text { process and must be held } \\
\text { accountable }\end{array}$ \\
\hline
\end{tabular}

${ }^{60}$ Kesselheim \& Outterson, supra note 2; Improving Antibiotic Markets, supra note 34, at 146-47. 


\begin{tabular}{|l|l|l|}
\hline 5. Maximize global health & $\begin{array}{l}\text { aHIF payment and } \\
\text { conservation targets would } \\
\text { be based on global health } \\
\text { impact; aHIF becomes an } \\
\text { effective global coordination } \\
\text { mechanism independent of } \\
\text { the quality of local } \\
\text { governmental support or } \\
\text { competence }\end{array}$ & $\begin{array}{l}\text { Targets must be set } \\
\text { appropriately, without } \\
\text { company gaming; } \\
\text { surveillance likewise must } \\
\text { be independent and reliable }\end{array}$ \\
& \\
&
\end{tabular}

First, companies would have a significant financial incentive to manage their antibiotics for long-term public health, rather than short-term sales. Companies would benefit most from getting the right drug to the right person at the right price, and would deploy their remarkable marketing talents to discourage inappropriate use. Companies might also make strategic market decisions. For example, Bayer owned the patents on both ciprofloxacin and a related antibiotic used in agriculture. The battle to restrict non-therapeutic uses of antibiotics in animal feeds would be transformed if the company's profits from exploitation of these two products were contingent on meeting conservation goals. In the current regulatory battle over animal antibiotics, the government and companies question each other's data; in the aHIF, companies would use their own private data to make decisions to forgo animal sales.

Second, as described above, the biology of resistance might require multiple companies to coordinate their actions in order to hit resistance targets, maximize health impact, and minimize antibiotic pollution. Limited antitrust waivers (or state action protection via the aHIF) may be required. Antibiotic pollution might require aHIF registration to be an all-or-nothing offer to all antibiotic drugs in a functional resistance group. Unlike other therapeutic categories, antibiotics in the aHIF face 
special challenges if some drugs are in the program but others - polluters with low health impact - remain outside. It should be noted that any company with an aHIFregistered antibiotic would have a clear incentive to manage its entire portfolio in order to achieve the aHIF resistance targets, even if it required changes to marketing plans for unregistered drugs. In this way, companies with one or more registered products would enjoy financial rewards for carefully managing even their antibiotics that are outside the aHIF.

It must be conceded that some companies might remain entirely outside the aHIF and yet choose to market their drugs in a fashion that polluted other antibiotics, including registered products. Such extreme cases might call for other remedies, including denying (or revoking) market access for such polluting, lowvalue drugs on public health grounds, or mandating registration with the aHIF. This is an empirical question that should not be answered a priori; we simply don't know yet whether cross-company antibiotic pollution from non-aHIF companies will undermine aHIF conservation goals to a significant degree.

Third, since resistance emerges gradually over time, the proper time frame for the aHIF might be much longer than ten years. If an antibiotic remained in the aHIF for 20 years or more with significant continuing health impact, then the company should continue to receive the reward, so long as it met the resistance targets. New antibiotics might be delayed, especially ones not quite as good as existing drugs, but that need not bother us. Indeed, social welfare over the coming decades would be enhanced by just such a delay, saving these drugs for a time when resistance to other drugs has improved the relative effectiveness of this new drug. 
In addition to stretching the aHIF reward period beyond the usual 10 years for antibiotics, one might also consider delaying the start of the aHIF period for some antibiotics that are not urgently required. Here the aim would be to encourage the innovator to delay efforts to achieve extensive use of its product to the future period in which such wide use can make the greatest contribution to global health. Limited use for extreme cases might be appropriate during these Strategic Antimicrobial Reserve periods.

Fourth, companies will be incentivized to solve many significant "last mile" problems in antibiotics. One such problem involves the availability of rapid pointof-care diagnostics to distinguish between viral and bacterial infections. In the absence of such a test, many clinicians resort to empiric therapy with broad spectrum antibiotics. Treating a virus with antibiotics does not affect the virus, but may negatively affect the health of the patient while also facilitating resistance. From the financial perspective of a drug company that is selling antibiotics under the current system of incentives, these diagnostics can only decrease its sales and are therefore financially undesirable. In contrast, under the aHIF, the company would have a significant financial incentive to promote appropriate use of diagnostics. Likewise, antibacterial vaccines dampen the demand for antibiotics by reducing the incidence of bacterial illness. Companies with antibacterial vaccines in the aHIF would be financially rewarded for preventing the spread of disease through vaccination. Similar infrastructure issues include infection control measures and resistance surveillance; these tasks do not have an insurance billing code in most countries and are frequently left to public health agencies with limited 
budgets. Companies with antibiotics in the aHIF would have a financial incentive to support these efforts in whatever way the companies thought maximized health impact. In a similar fashion, the companies would deploy their impressive marketing, public relations, and lobbying operations in support of antibiotic conservation, rather than opposing these efforts through aggressive marketing and other tools.

Finally, most current efforts to conserve antibiotics are not global in scope. Global coordination is a significant collective action problem, akin to unregulated depletion of fisheries or pollution that falls on distant countries. Many of the benefits of antibiotic use are internalized, but many of the costs are externalized. The WHO's program in 2011-2012, while laudable in aspirations, is not well funded and lacks both enforcement and norm-setting mechanisms. The aHIF could serve a significant global coordination role here, leveraging funding from the aHIF sponsors into a true global strategy implemented with the enthusiastic support of private actors. The aHIF would give the global drug companies a direct stake in reducing the global health impact of communicable bacterial diseases while managing the common pool resource of antibiotics for the long-term health of the global population. The companies are well positioned to influence the utilization of their products in every region of the planet. Since the companies themselves largely undertake the task, this mechanism can succeed without regard to the quality of local governance institutions. The aHIF is therefore scalable throughout the world, despite weak health governance in many countries. 


\section{Patent-related issues for the aHIF}

As described above, the precise patent policy of the HIF is not an essential design feature, but a functional and practical choice at this stage. We can think of several reasons why various patent policies might work with the HIF generally, but in many cases the analysis is significantly different for the aHIF.

First, by transferring the patent, the company would lose the right to control certain follow-on innovations, which are commercially important in many drug classes. For the aHIF, this issue may be less salient, as a successful aHIF will delay the clinical and financial need for follow-on antibiotics. In antibiotics, we don't necessarily want to promote additional drugs in class on an accelerated timetable. Society may be better off with spreading antibiotic approvals across a larger number of years, coupled with strong conservation incentives. In any event, the aHIF might need to be an all-or-nothing program, especially if cross-drug and crossclass pollution could not otherwise be controlled.

Second, retaining the patent gives the company additional control over operational issues such as how the drug is used in drug combinations, with companion diagnostics, and potential early exit rights under the aHIF contract. All of these issues are enmeshed with the antibiotic pollution externalities described above: in many cases, combination drugs offer much lower resistance profiles; companion diagnostics targets the right drug against the right bug without inappropriate use; but early exit may need to be discouraged or contractually limited in order to protect drugs remaining in the aHIF from pollution. 
One advantage of an immediate transfer (or open license) of the patent for a HIF-registered product is that it shifts competition from the molecule to finding more efficient manufacturing methods that might significantly reduce the marginal cost of production. While the company contractually promises production at marginal cost, the HIF does not necessarily create competitive conditions wherein companies strive to drive those costs down. In economic terms, the HIF will address the great majority of the deadweight loss associated with patent-based pricing, but may forego some opportunities for additional social welfare gains through reduced marginal costs. Insofar as manufacturing is outsourced, the incentive to reduce the marginal cost of production for HIF-registered products is powerful, as competing manufacturers will want to be able to submit the lowest bid. Insofar as manufacturing is not outsourced, the firm will still want to lower its manufacturing cost. For even if the firm's best option is to sell at cost, regardless of what this cost is, the firm will achieve more health impact if the product is sold at a lower price. The firm is better off producing and selling at $\$ 4$ than at $\$ 5$.

In the context of antibiotics, these issues are muted somewhat, since maximizing production volume and minimizing unit costs are not the primary objectives. Indeed, universal misuse of free antibiotics would be a public health problem. A key issue here is that while the aHIF could stretch out or delay the reward period for antibiotics, such that the incentives for conservation were adequate, patents would inevitably expire, opening a path for uncontrolled generic production. Therefore, to the extent that cross-molecule and cross-class pollution cannot otherwise be controlled, a key component of antibiotics in the aHIF would be 
an international agreement not to permit other firms to sell aHIF-rewarded antibiotics, regardless of the patent status. Put another way, pollution externalities might require all antibiotics to be in the aHIF.

Some have suggested longer patents for antibiotics. ${ }^{61}$ Without the aHIF, simply extending exclusivity rights is a non-starter, since it opens up opportunities for exploitation of consumers by innovators without any clear conservation gains. ${ }^{62}$ Within the aHIF mechanism, extending exclusivity rights is consistent with maintaining roughly the same level of profits while improving clinical and conservation outcomes.

James Love has criticized the HIF for not relying on generic production to ensure the lowest possible marginal cost of production. ${ }^{63}$ As discussed above, we find these concerns to be addressed by the companies' incentives to realize the greatest health impact at the lowest possible contractual price. But in the context of antibiotics, this criticism gains even less traction. Global public health is clearly advanced by wide dissemination of quality generic statins to treat cardiovascular disease; the same cannot be said for antibiotics with resistance problems. We suggest that unconstrained generic production of antibiotics might make the global conservation effort more difficult, tipping the long-term ecological and evolutionary balance in the wrong direction. Further research is clearly needed on this question.

Finally, the patent holder may hesitate to transfer the patent in advance of the 10-year HIF reward payments. The HIF will gain credibility as a counterparty

${ }^{61}$ Eric Kades, Preserving a Precious Resource: Rationalizing the Use of Antibiotics, 99 Nw. UnIV. L. Rev. 611 (2005); Infectious Diseases Society of America, supra note 1.

${ }^{62}$ Vanishing Public Domain, supra note 28.

${ }^{63}$ See Love, supra note 22. 
over time, so perhaps this issue will diminish in importance in future years. Antibiotics do not appear to present novel questions for this specific issue.

\section{Conclusion}

The antibiotic sector is an attractive but complex candidate for testing the Health Impact Fund. Poor market incentives have led both industry and academic researchers to suggest de-linkage mechanisms as a means to simultaneously address problems with conservation and R\&D. The looming crisis of antibiotic resistance is an important global problem. Resistant diseases are significant health risks throughout the world. This problem threatens both high- and low-income populations, and it may prove impossible to solve without an effective global coordination mechanism. The aHIF demonstration, while modestly sized compared to global pharmaceutical markets, is probably large enough to alter incentives in the antibiotic sector. Some of the criticisms raised about the HIF apply with less force in the antibiotic sector, making it an attractive candidate for a full-scale test.

The aHIF is not without significant challenges. Financing must be robust and sustainable. Adequate and realistic resistance targets will have to be set globally, without political meddling. Achieving these targets will be partially delegated to the companies, but they will also be accountable to the aHIF for failing to hit the mark. Drug companies will therefore be encouraged to cooperate for global public health in unprecedented ways, with equally impressive impacts on global health. 
The aHIF can serve a key role as a global coordination mechanism for antibiotics, ensuring that this important drug class does not fade away, but continues to serve humanity. 